\title{
Dilatometric study of the phase transformations under conditions of recrystallized and non-recrystallized austenite in $3 \mathrm{Mn}-1.5 \mathrm{Al}$ steel
}

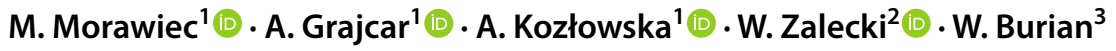

Received: 28 March 2020 / Accepted: 13 November 2020 / Published online: 12 December 2020

(c) The Author(s) 2020

\begin{abstract}
This work presents the results of prior austenite state on the phase transformation behavior in a medium manganese steel alloyed with Al. The austenite was plastically deformed at two different temperatures. The first was at $1050{ }^{\circ} \mathrm{C}$ to ensure its recrystallization before cooling. The second treatment included deformation at $900{ }^{\circ} \mathrm{C}$ to keep high dislocation density in the austenite. The analysis of recrystallization process or its lack on the phase transformation behavior was analyzed. The study included thermodynamic calculations to analyze proper conditions of selected heat treatments. The dilatometric analysis of the phase transitions dependence on deformation temperatures was carried out. Deformation continuous cooling transformation diagrams were formed on this basis. The metallographic investigations were performed to determine microstructure constituents after cooling. The investigation proved the presence of ferrite untransformed during the austenitization step at $1100{ }^{\circ} \mathrm{C}$. The dominant phase was bainite which was kept present up to $100{ }^{\circ} \mathrm{C} \mathrm{s}^{-1}$ cooling rate. The amount of martensite increased with increasing the cooling rate. For the non-recrystallized austenite, more bainite was present in the microstructure for higher cooling rates compared to the recrystallized one. This was the result of higher density of preferable places for bainite nucleation in the non-recrystallized austenite. The Vickers hardness measurements were conducted after the applied heat treatments. The hardness of steel increased together with applying the higher cooling rates, which corresponded to the higher martensite amount. These values were higher for the non-recrystallized austenite because of higher dislocation density.
\end{abstract}

Keywords Medium manganese steel $\cdot$ Hot deformation $\cdot$ Recrystallization $\cdot$ Dilatometric study $\cdot$ Phase transformation kinetics

\section{Introduction}

Environmental and safety requirements in automotive industry contribute to the development of new grades of Transformation Induced Plasticity (TRIP) steels. A desirable feature of modern steels is high strength without deterioration in plasticity. It allows reducing sheet thickness resulting in significant mass reduction of car's body components [1-4].

M. Morawiec

mateusz.morawiec@polsl.pl

1 Department of Engineering Materials and Biomaterials, Silesian University of Technology, 18a Konarskiego Street, Gliwice, Poland

2 Institute for Ferrous Metallurgy, Łukasiewicz Research Network, 12-14 K. Miarki Street, Gliwice, Poland

3 Institute of Non-Ferrous Metals, Łukasiewicz Research Network, 5 Sowińskiego Street, Gliwice, Poland
Recently, medium manganese steels containing 3-5\% Mn have attracted growing attention due to their beneficial combination of strength and ductility obtained at relatively low production costs. Manganese is a major alloying element, which enables obtaining retained austenite (RA) in a final microstructure. However, for further stabilization of retained austenite $\mathrm{Si}$ and/or $\mathrm{Al}$ is needed. Both elements prevent carbide formation during bainite formation [5]. This leads to the excess of carbon, which remains in the austenite increasing its thermal stability. Unfortunately, silicon has the negative impact on hot-dip galvanizing of the steel sheets due to oxide forming behavior. These oxides deteriorate the sheet wettability and obtaining the good quality of the steel sheets [6]. Therefore, silicon is often replaced by Al, which does not exhibit this kind of the negative impact. Moreover, aluminum decreases the density of the steel, which further decreases the mass of the car body construction [7]. Sometimes, the additions of $\mathrm{Mo}, \mathrm{Nb}$, Ti are added for the improvement of strength levels [8]. The retained austenite is crucial 
for mechanical behavior of such multiphase steel sheets, when is distributed as blocky grains or layers within ferritic, bainitic or martensitic matrices [2,8-10]. The RA can be stabilized by the combination of the $\mathrm{C}$ and $\mathrm{Mn}$ enrichment, which requires a multi-step heat treatment from an austenitizing temperature. The good combination of strength and ductility as well as the proper deformability of multiphase steel sheets is achieved when the $10-15 \%$ retained austenite remains in the bainitic or martensitic matrixes. Such multiphase microstructures are characterized by the proper homogeneity and beneficial conditions for strain-induced martensitic transformation of layered retained austenite during plastic deformation (stamping, bending, etc.) $[1,4]$. The presence of retained austenite is strictly related to ensuring a lack of carbides in the bainitic microstructures [5].

Application of thermal analysis methods and thermodynamic calculations are helpful in designing suitable heat treatment profiles during cooling. It can be obtained by using the dilatometric analysis to determine critical transformation temperatures. Results of investigations should be supported by detailed microstructural observations. Phase transformations in multiphase steels are very complex due to various morphologies of RA, which occurs in a form of thin layers or blocky grains [11-13]. The especially important factor is a state of the austenite before continuous or isothermal cooling to room temperature. In general, the ferritic and bainitic transformations are accelerated by plastic deformation, which takes place, for example, during finishing hot rolling $[9,11]$. On the other hand, the effect of plastic deformation on the stability of retained austenite is not still clear.

In the present paper, the austenite decomposition and subsequent phase transformations during cooling the $3 \mathrm{Mn}-1.5 \mathrm{Al}$ steel were analyzed. The phase transformations were investigated under conditions of recrystallized and nonrecrystallized austenite by using dilatometric analysis. The effect of deformation temperature and resulting austenite state on the phase transitions was studied. This is important in terms of the design of multi-step cooling schedules required for this new group of high-strength medium-Mn steels.

\section{Experimental}

The medium manganese steel containing $0.17 \mathrm{C} \%, 0.22 \mathrm{Si} \%$, $3.3 \mathrm{Mn} \%, 0.23 \mathrm{Mo} \%, 1.7 \mathrm{Al} \%$ was produced as the laboratory vacuum induction-melted ingot (Balzers VSG-50 furnace) with dimensions of $\varnothing 124 \mathrm{~mm} \times 200 \mathrm{~mm}$. This was forged (high-speed hydraulic press, Kawazoe) in the temperature range between $1200{ }^{\circ} \mathrm{C}$ and $900{ }^{\circ} \mathrm{C}$ to a final thickness of $22 \mathrm{~mm}$. After the forging finish, the cooled samples showed the full martensitic microstructures [11] due to the strong hardenability of manganese addition.
The JMatPro (database ver. 11.2) and ThermoCalc (steel and Fe-alloys database-TCFE9) software packages were used as a first step of the analysis to determine experimental parameters of the heat treatment. In this way, heat treatment profiles were defined without numerous dilatometric trials. The highest and lowest cooling rates as well as austenitization temperatures were set in this way.

Next, the machined samples were subjected to dilatometric studies using a high-resolution BAHR dilatometer DIL805A/D. The samples of $10 \mathrm{~mm}$ in length and $5 \mathrm{~mm}$ in diameter were prepared for the dilatometry analysis by machining the forged flats. The heat treatment was performed under vacuum, and the cooling medium was helium. The dilatometric analysis was carried out to determine the effect of austenite state prior to cooling on critical temperatures of phase transitions. Figure 1 presents the heat treatment used for the mentioned analysis. The material was heated to $1100{ }^{\circ} \mathrm{C}$ at a rate of $3{ }^{\circ} \mathrm{C} \mathrm{s}^{-1}$ within $360 \mathrm{~s}$ and held at this temperature for $300 \mathrm{~s}$. Then, the material was cooled down at a rate of $5{ }^{\circ} \mathrm{C} \mathrm{s}^{-1}$ to deformation temperature of $900{ }^{\circ} \mathrm{C}$ and $1050^{\circ} \mathrm{C}$ (Fig. 1).

The samples were subjected to the axisymmetric compression using the conventional deformation unit of the DIL805A/D dilatometer. The strain was 0.5 at a rate of $1 \mathrm{mms}^{-1}$. After the deformation continuous cooling to room temperature was applied. The used cooling rates were from $0.5^{\circ} \mathrm{C} \mathrm{s}^{-1}$ up to $100{ }^{\circ} \mathrm{C} \mathrm{s}^{-1}$.

After the dilatometric studies, the samples were cut in half for metallographic preparations. The samples were ground with the use of 220,500, 800, and 1200 granularity papers. Then the polishing with 3 and $1 \mu \mathrm{m}$ diamond solution was performed. Finally, the samples were etched with $2 \%$ Nital solution. The microstructure characterization was performed using the Zeiss Axio Observer Z1m with the system for digital analysis. The surface topography and

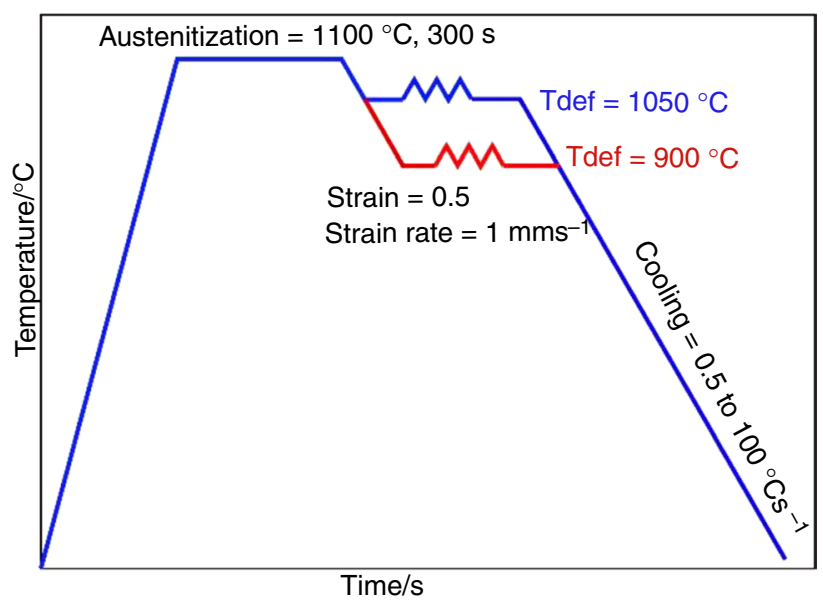

Fig. 1 Heat treatment used in the dilatometric studies 


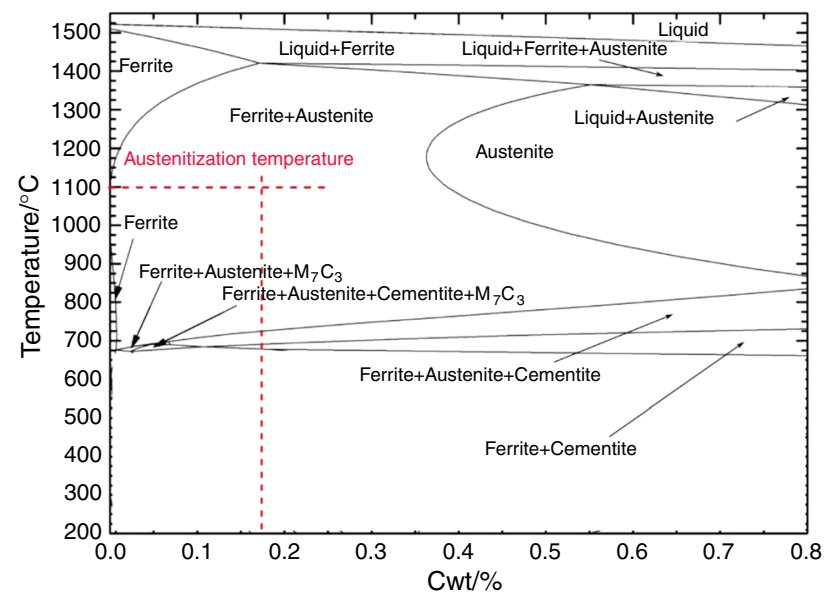

Fig. 2 Pseudo-binary diagram of the analyzed steel calculated using ThermoCalc

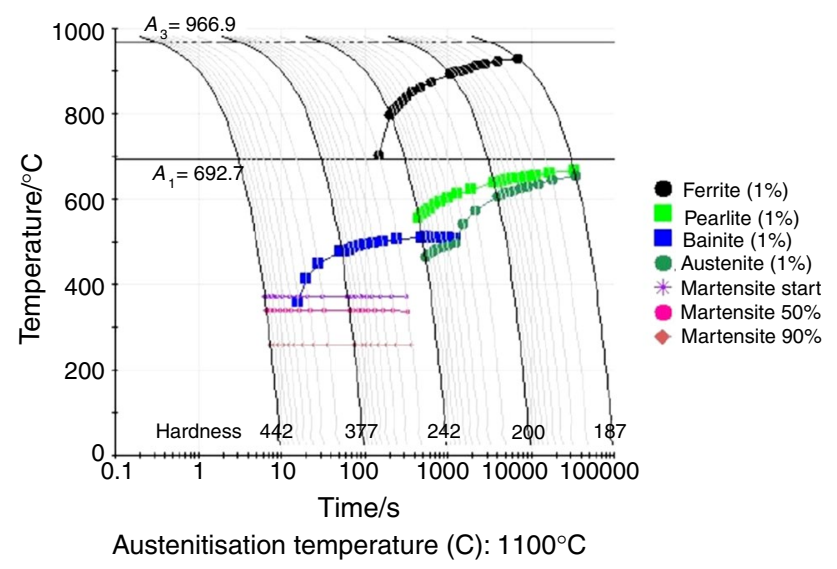

Fig. 3 CCT diagram calculated using the JMatPro software

thickness of martensitic/bainitic laths were estimated using the atomic force microscope (XE-100 Park Systems). The morphology of structural constituents was revealed using the transmission electron microscopy (JEOL JEM 200CX). Hardness measurements were carried out for all cooling rates. The Vickers method (Future-Tech FM-700) was used with a load of $100 \mathrm{~N}$ and the dwell time of $15 \mathrm{~s}$.

\section{Results and discussion}

\section{Thermodynamic calculations}

The first step was thermodynamic calculations carried out using ThermoCalc (steel and Fe-alloys database-TCFE9) and JMatPro (database ver. 11.2) software packages. The results of the calculations are presented in Figs. 2 and 3.
Figure 2 presents the pseudo-binary $\mathrm{Fe}-\mathrm{C}$ diagram of steel calculated using the ThermoCalc. The investigated steel solidifies by a $\delta$-ferrite, which transforms at app. $1400{ }^{\circ} \mathrm{C}$ into austenite. However, it can be observed that there is no single $\gamma$ region below the solidus line. There is a large twophase thermodynamic equilibrium of $\alpha$ and $\gamma$ phases. It is due to high concentration of $\mathrm{Al}$, which is one of the most vital ferrite stabilizers $[14,15]$. Therefore, the $A_{\mathrm{e} 3}$ temperature cannot be indicated for the alloy containing $0.17 \%$ $\mathrm{C}$ (Fig. 2). Moreover, an increase in Al content leads to the higher martensite and bainite start temperatures [14]. $\mathrm{Al}$ is one of two elements (the second one is $\mathrm{Co}$ ) shifting these critical temperatures. However, because manganese is an austenite stabilizer, its higher amount decreases $A_{\mathrm{e} 1}$ temperature corresponding to the beginning of cementite precipitation $[16,17]$. The $A_{\mathrm{e} 1}$ temperature is $\sim 700{ }^{\circ} \mathrm{C}$ for the steel containing $0.17 \% \mathrm{C}$. Manganese affects also the start temperatures for martensite and bainite transformations [18].

According to the thermodynamic calculations, the martensite start temperature increases when the $1.7 \% \mathrm{Al}$ content is added. The $M_{\mathrm{s}}$ temperature for the steel without $\mathrm{Al}$ is $319^{\circ} \mathrm{C}$ and increases to $371{ }^{\circ} \mathrm{C}$, when aluminum is added. The opposite effect takes place in the case of manganese. The addition of 3.3\% Mn leads to the drop in $M_{\mathrm{s}}$ temperature from $551{ }^{\circ} \mathrm{C}$ (without Mn) to $371{ }^{\circ} \mathrm{C}$. This shows that manganese has the higher impact on these temperatures than $\mathrm{Al}$ in this steel. According to the presented diagram, the selected austenitization temperature of $1100{ }^{\circ} \mathrm{C}$ does not ensure a full austenite microstructure due to the high aluminum content. The microstructure is composed of austenitic-ferritic mixture. It means that some ferrite formed during austenitization should be expected at room temperature after cooling.

The calculated CCT diagram (Fig. 3) shows the continuous cooling transformation diagram of the steel austenitized at $1100{ }^{\circ} \mathrm{C}$. The high content of Mn shifts ferritic and bainitic areas into right, which is caused by the potent hardenability effect of manganese [19,20]. This alloying element leads also to the reduction in the pearlite transformation start below $700{ }^{\circ} \mathrm{C}$. The ferritic and pearlitic transformations initiated after such long time of $100 \mathrm{~s}$ and $300 \mathrm{~s}$ are a good basis for production of bainitic structures without ferrite and pearlite [21, 22]. The bainitic area is shifted to the left side and its highest start temperature is equal to $535{ }^{\circ} \mathrm{C}$, whereas the martensite start temperature is equal to $371{ }^{\circ} \mathrm{C}$. The bainite start temperature decreases together with increasing the cooling rate. This is the result of longer time necessary to start the carbon diffusion and formation of bainite. This results in lower amount of bainite that is formed during cooling at higher cooling rates [23]. 


\section{Dilatometric study}

The dilatometric study for two variants of deformation was performed. Figure 4 presents an example of one of dilatometric curves used for creation of DCCT diagrams. These curves allow for the determination of phase transformation start and finish temperatures [21, 24]. According to the presented curve, the martensite start temperature at the deformation temperature of $900{ }^{\circ} \mathrm{C}$ is $374{ }^{\circ} \mathrm{C}$. Based on these curves, the bainite and martensite start and finish temperatures were determined. The dilatation signal in Fig. 4a from the martensitic transformation is clear. The more advanced dilatometric response is from the bainitic transformation. Some serration behavior in Fig. $4 \mathrm{~b}$ indicates a step-like character of the bainitic transformation with presumable precipitation of carbides in bainite [17]. It means that the continuous cooling is not effective in producing carbide-free bainite. The characteristic temperatures determined by the dilatometry technique for the recrystallized and non-recrystallized austenite together with the calculated temperatures are presented in Table 1 .
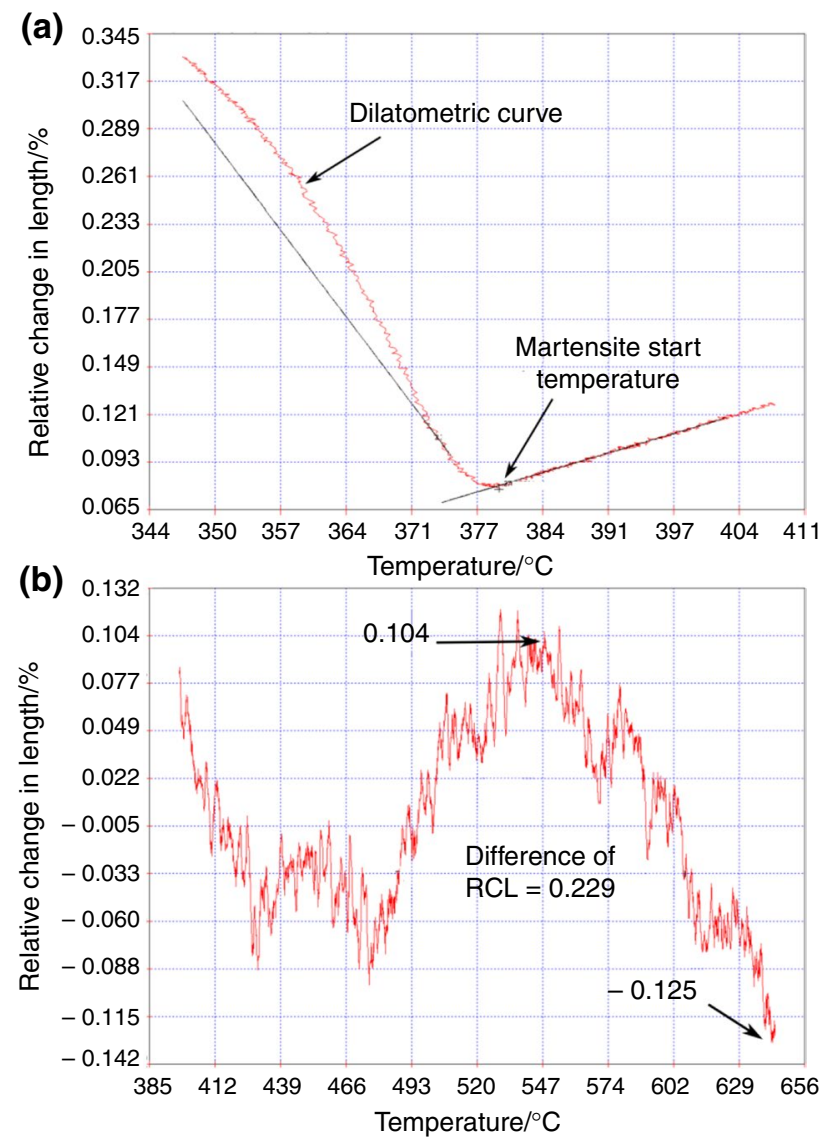

Fig. 4 Dilatometric curves for the steel deformed at $900{ }^{\circ} \mathrm{C}$ and cooled at a rate of $1{ }^{\circ} \mathrm{C} \mathrm{s}^{-1}$ : a a part corresponding to martensite formation, $\mathbf{b}$ a part corresponding to bainite formation
Table 1 Experimental and calculated critical temperatures of steel

\begin{tabular}{llll}
\hline $\begin{array}{l}\text { Critical } \\
\text { tempera- } \\
\text { ture }\end{array}$ & $\begin{array}{l}\text { Recrystallized } \\
\text { austenite } /{ }^{\circ} \mathrm{C}\end{array}$ & $\begin{array}{l}\text { Non-recrys- } \\
\text { tallized } \\
\text { austenite } /{ }^{\circ} \mathrm{C}\end{array}$ & $\begin{array}{l}\text { Calculated tem- } \\
\text { perature using } \\
\text { JMatPro } /{ }^{\circ} \mathrm{C}\end{array}$ \\
\hline$A_{1}$ & 633 & 633 & 692 \\
$B_{\mathrm{s}}$ & 600 & 590 & 535 \\
$\mathrm{~B}_{\mathrm{f}}$ & 376 & 365 & 371 \\
$M_{\mathrm{s}}$ & 376 & 365 & 371 \\
$M_{\mathrm{f}}$ & 160 & 165 & 150 \\
\hline
\end{tabular}

These results show that the calculated and experimental temperature values are in good agreement. The only discrepancy is present in the case of $A_{1}$ and $B_{\mathrm{s}}$ temperatures. This is due to two reasons. The different heating conditions and the high $\mathrm{Al}$ and $\mathrm{Mn}$ additions, which are not still good enough reflected in the thermodynamic databases. The calculations are made for the equilibrium conditions, whereas the real heating was faster. This leads to a difference in experimental and calculated $A_{1}$ temperatures. Moreover, the model used in the JMatPro has some problems with the accuracy in the case of medium manganese contents in advanced steels. Hence, the results for phase transformation behavior can differ between real and calculated values. This results also in mentioned above differences in $B_{\mathrm{s}}$ temperature.

According to the obtained results (Fig. 5), a deformation temperature has some impact on phase transitions. According to the presented DTTT diagram, the main structural constituent is bainite, which is present for a whole cooling range. When the cooling rate exceeds $100{ }^{\circ} \mathrm{C} \mathrm{s}^{-1}$, the only phase present in the microstructure is martensite.

Plastic deformation at $1050{ }^{\circ} \mathrm{C}$ shifts the bainite region to lower cooling rates and slightly higher temperatures. However, the bainite start temperature decreases for higher cooling rates. According to Xiao et al. [23], this is because the bainite transformation occurs not only by shear transformation but also by carbon diffusion and carbide precipitation. This complex mechanism causes conditions when the bainite transformation response to strain depends on loading and transformation conditions. In the case of carbon, a faster cooling rate reduces the possible time for carbon diffusion. Therefore, longer time is necessary for bainite transformation to start. Hence, the lower bainite start temperature is detected. However, this change is small and does not have so much impact on the bainite amount at room temperature. The martensite start and finish temperatures are very similar for both deformation temperatures. Yet, the increase of it in the case of $1050{ }^{\circ} \mathrm{C}$ corresponds to the results of Kawulok et al. [25]. In their work, a higher deformation temperature leads to the higher martensite start temperature. This phenomenon depends on the combined effects of austenitization temperature 


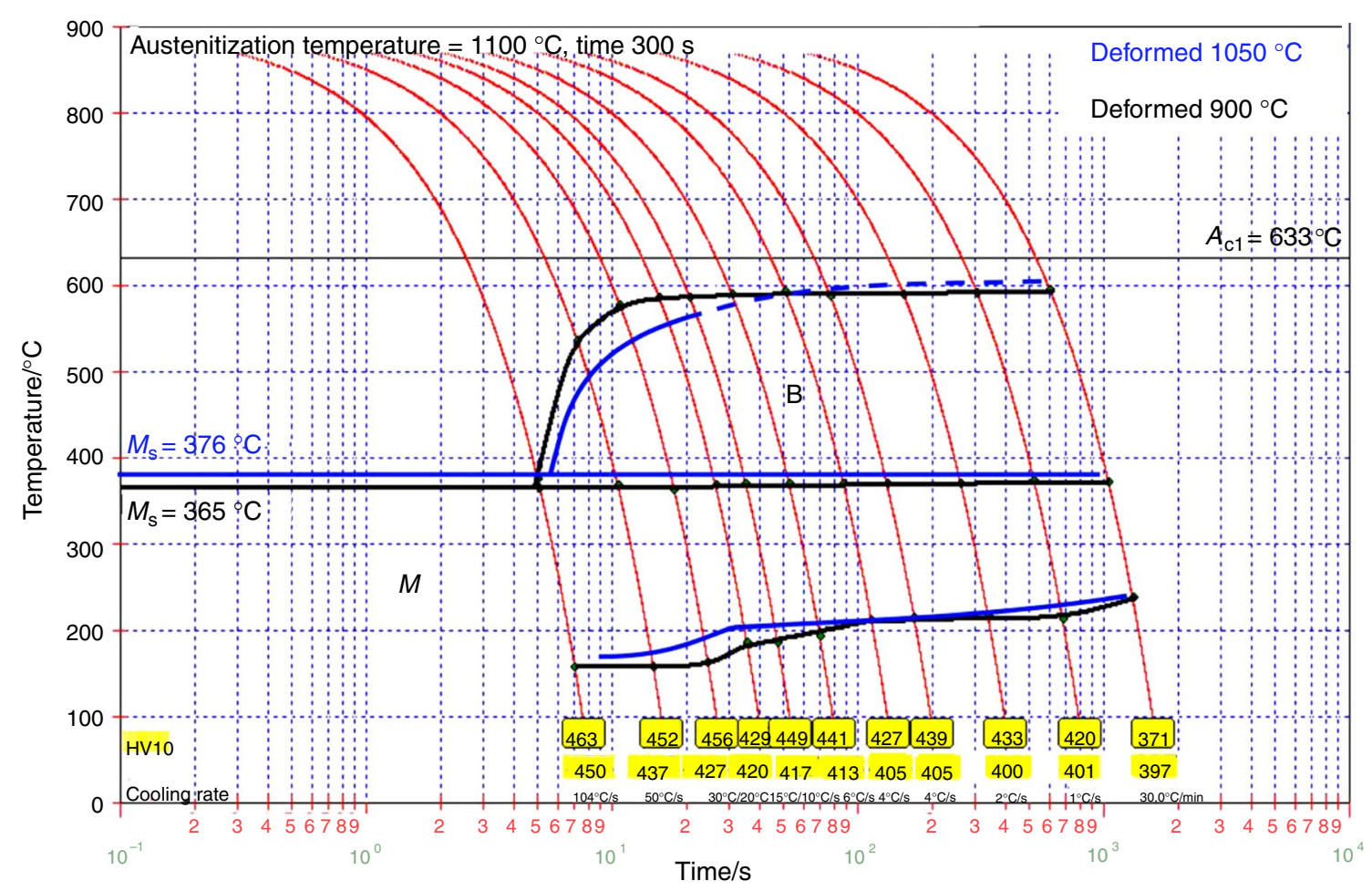

Fig. 5 DCCT diagrams of analyzed steel subjected to deformation at $1050{ }^{\circ} \mathrm{C}$ and $900{ }^{\circ} \mathrm{C}$

and deformation. The difference in phase transformation behavior comes from different states of the austenite prior to cooling. At $1050{ }^{\circ} \mathrm{C}$, the deformed austenite undergoes recrystallization (at least partial recrystallization), which decreases dislocation density and refines a grain size. At $900{ }^{\circ} \mathrm{C}$, no recrystallization occurs and the austenite has the higher dislocation density compared to $1050{ }^{\circ} \mathrm{C}$. This phenomenon is schematically shown in Fig. 6.
Fig. 6 Schematic presentation of the austenite state at different deformation temperatures

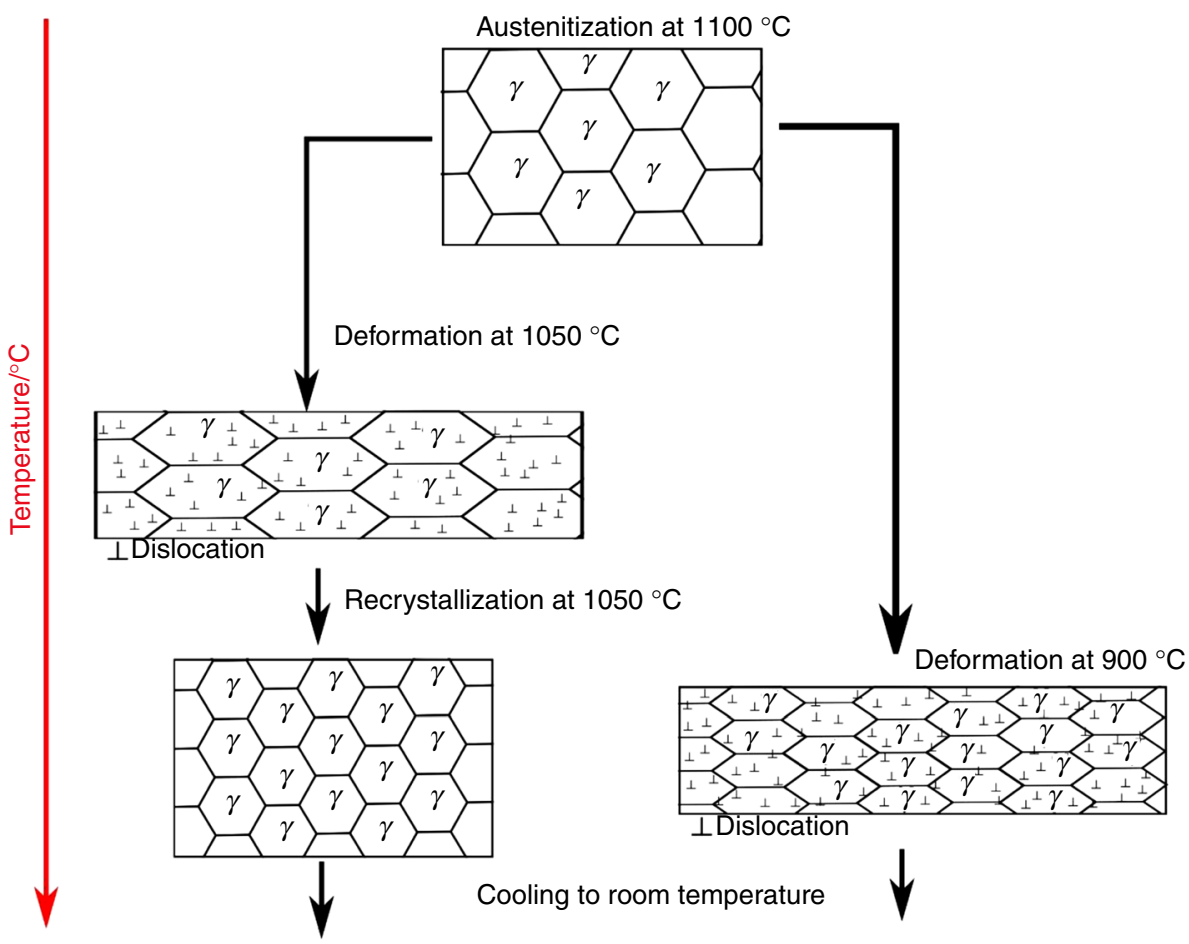


(a)

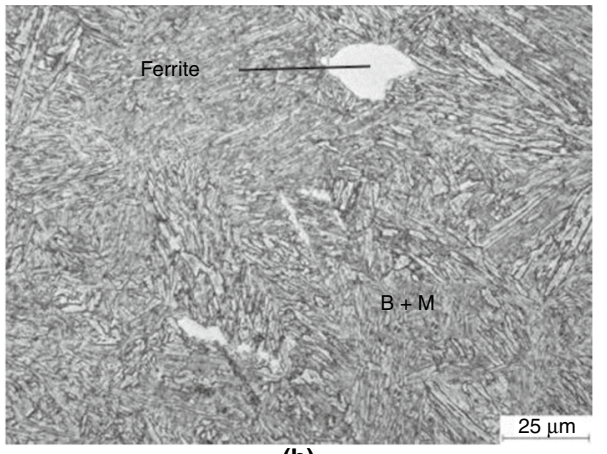

(b)

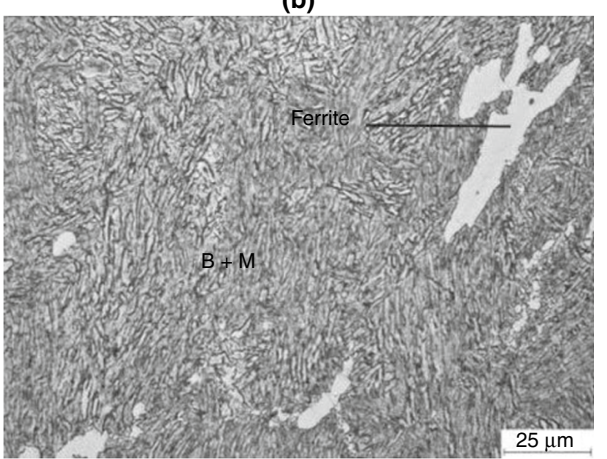

(c)

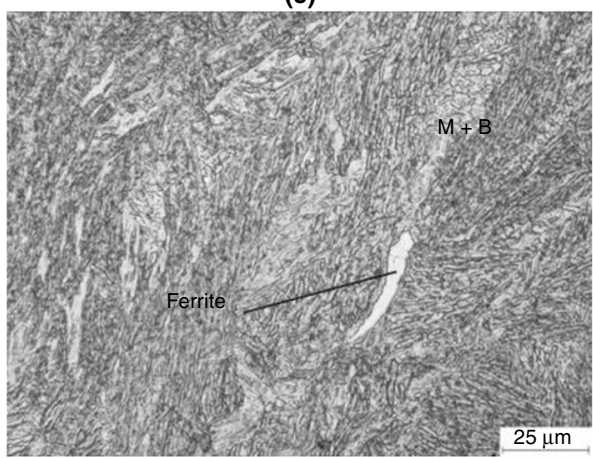

Fig. 7 Microstructures of samples deformed at $900{ }^{\circ} \mathrm{C}$ and cooled at various rates to room temperature: $0.5^{\circ} \mathrm{C} \mathrm{s}^{-1}$ (a), $10{ }^{\circ} \mathrm{C} \mathrm{s}^{-1}$ (b) and $100{ }^{\circ} \mathrm{C} \mathrm{s}^{-1}$ (c); M-martensite, B-bainite

According to this mechanism, after recrystallization the austenite should have a smaller grain size than before deformation. The austenite shows a thermal stability dependence on a grain size. Matsuoka et al. [26] showed that the smaller grain size of austenite enhances its thermal stability. According to this after recrystallization, the stability of austenite should be higher (small grains) prolonging the necessary time for transformation to occur. Moreover, the non-recrystallized austenite has higher dislocation density, (a)

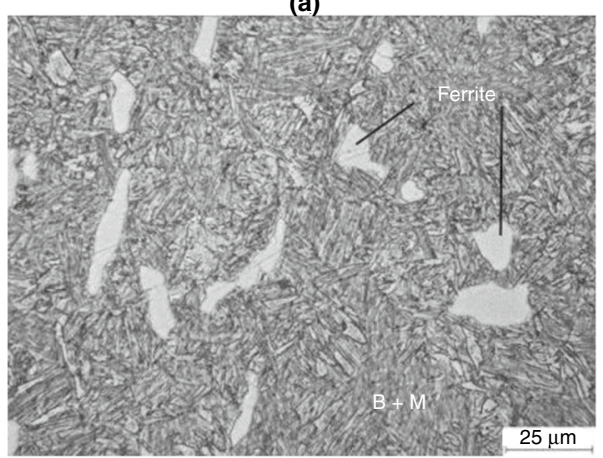

(b)

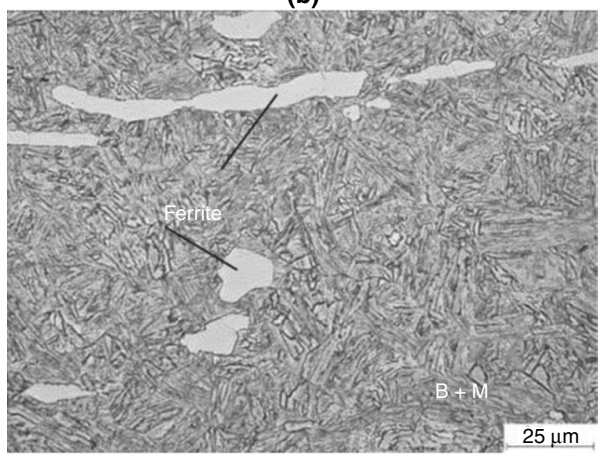

(c)

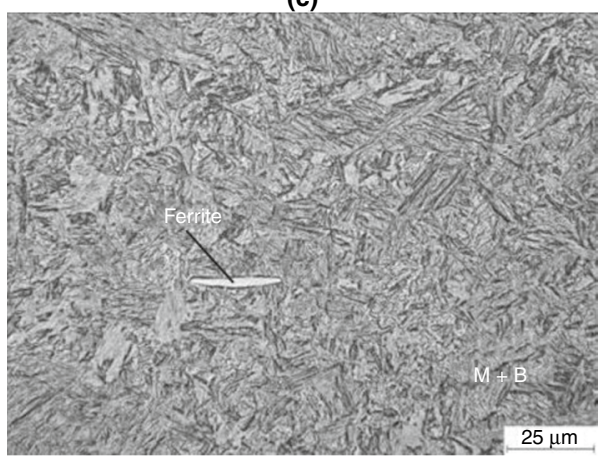

Fig. 8 Microstructures of samples deformed at $1050{ }^{\circ} \mathrm{C}$ and cooled at various rates to room temperature: $0.5{ }^{\circ} \mathrm{C} \mathrm{s}^{-1}$ (a), $10{ }^{\circ} \mathrm{C} \mathrm{s}^{-1}$ (b) and $80{ }^{\circ} \mathrm{C} \mathrm{s}^{-1}$ (c); M-martensite, B-bainite

which increases the amount of preferable places for bainite nucleation $[27,28]$. This explains why the bainite transformation rate is slightly higher at $900{ }^{\circ} \mathrm{C}$.

\section{Microstructure characterization}

Results of microstructural observations show that both plastic deformation temperature and cooling rate affect the microstructure of investigated steel. Figure 7 shows the microstructures of specimens deformed at $900{ }^{\circ} \mathrm{C}$. At this temperature, the recrystallization did not occur. 
Fig. 9 SEM micrographs of the sample deformed at $1050{ }^{\circ} \mathrm{C}$ and cooled to room temperature at $20^{\circ} \mathrm{C} \mathrm{s}^{-1}$ (a) and $2{ }^{\circ} \mathrm{C} \mathrm{s}^{-1}$ (b); $\mathrm{M}-$ martensite, $\mathrm{B}$-bainite
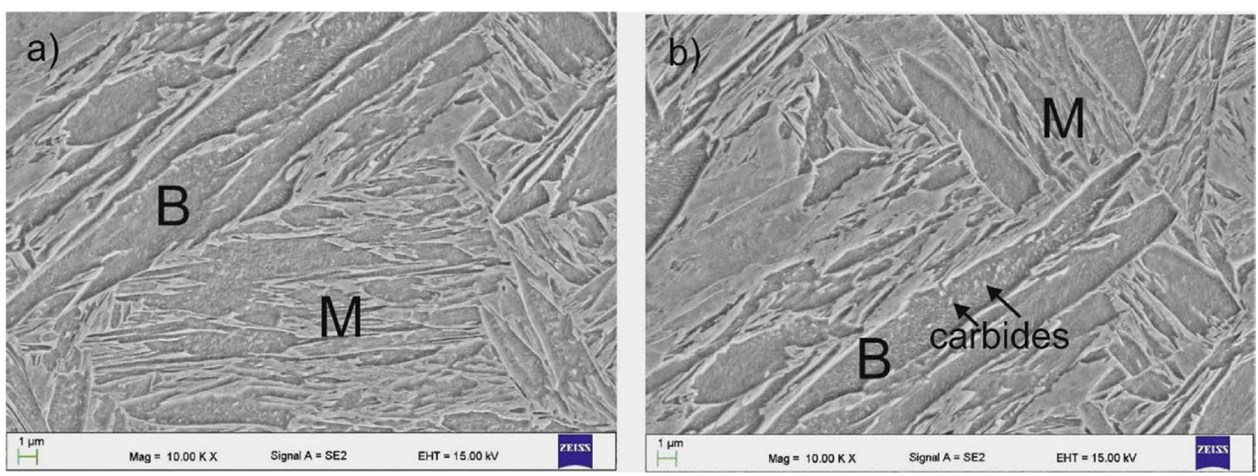

Fig. 10 Atomic force microscopy maps of the sample deformed at $900{ }^{\circ} \mathrm{C}$ and cooled to room temperature at $2{ }^{\circ} \mathrm{C} \mathrm{s}^{-1}$ : 2D surface topography (a), 3D surface topography $(\mathbf{b})$; RAretained austenite, $\mathrm{M}-$ martensite, B-bainite
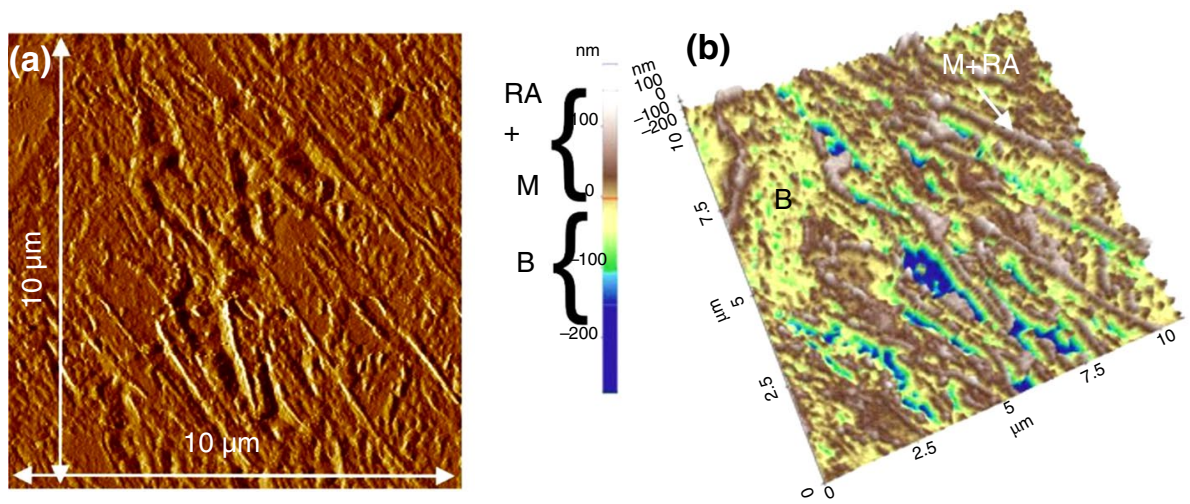

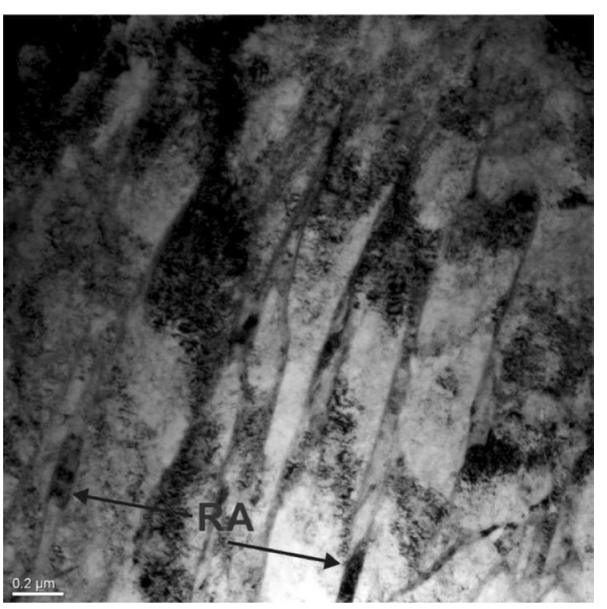

Fig. 11 Morphological features of bainitic-martensitic laths with retained austenite (RA) of the sample deformed at $900{ }^{\circ} \mathrm{C}$ and cooled to room temperature at $20^{\circ} \mathrm{Cs}^{-1}$

Figure 8 illustrates selected microstructures of specimens deformed at $1050^{\circ} \mathrm{C}$. In this case, the recrystallization took place. According to the results of dilatometric study (Fig. 5), the microstructures of specimens deformed at $900{ }^{\circ} \mathrm{C}$ and $1050^{\circ} \mathrm{C}$ are composed of bainite and martensite. The presence of thin laths of martensite and bainite can be observed in the microstructures. Regardless of deformation temperature, the presence of some fraction of ferrite was noted. However, this structural constituent was not formed as a result of the $\gamma \rightarrow \alpha$ transformation. This microstructural constituent was not transformed during austenitization of steel at $1100{ }^{\circ} \mathrm{C}$. The amount of ferrite is quite small. The ferrite fractions identified using the image analysis are between $2 \%$ and $9 \%$ independent of the deformation conditions and cooling rate. This phase is clearly visible as big oval grains. The size of ferrite grains corresponded to the high austenitization temperature. The martensite is a dominant microstructural constituent in the specimens cooled at the highest rate of 100 and $80{ }^{\circ} \mathrm{C} \mathrm{s}^{-1}$ (Figs. 7c, 8c, respectively). Bainite is dominant for the lowest cooling rates (Figs. 7a, 8a). The most fine-grained microstructure was obtained after deformation of steel at the temperature of $900{ }^{\circ} \mathrm{C}$ (Fig. 7) below the recrystallization temperature of $\gamma$ phase.

The details of the microstructures can be seen after applying the scanning electron microscopy (SEM). 
Fig. 12 Hardness measurements of steel after deformation at 1050 and $900{ }^{\circ} \mathrm{C}$

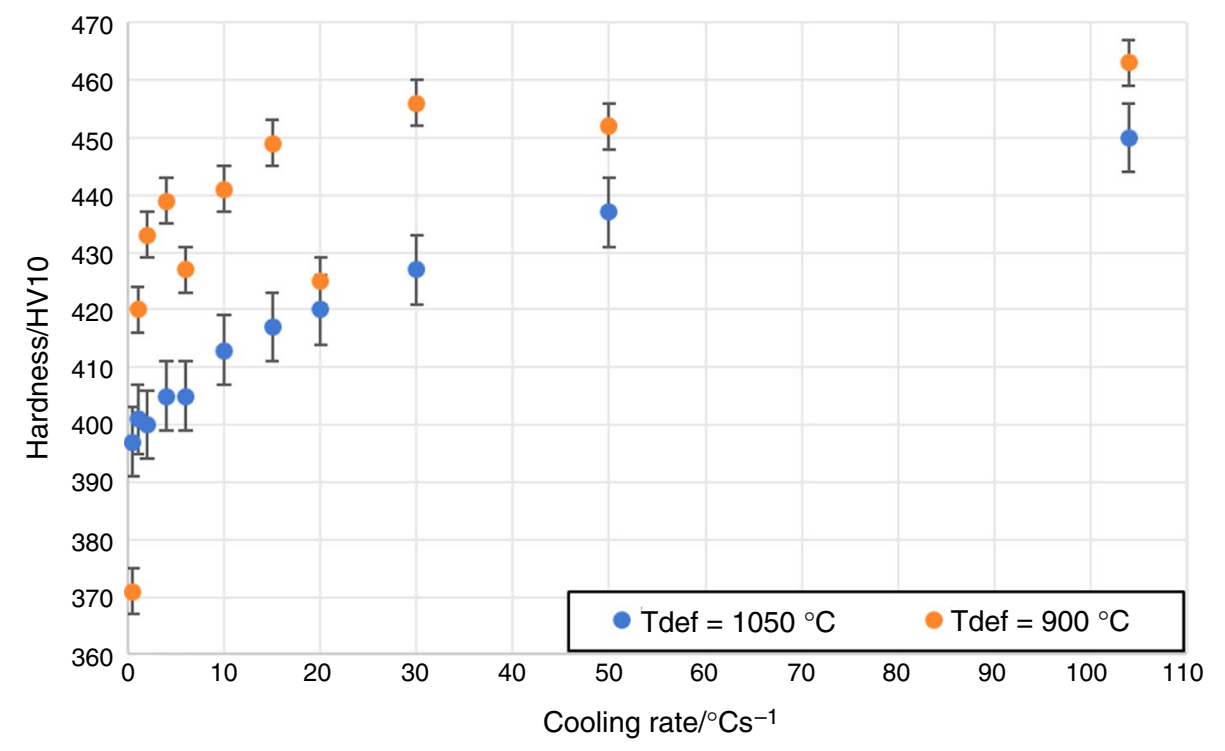

Figure 9 shows the SEM micrographs of the samples cooled at rates of $20^{\circ} \mathrm{C} \mathrm{s}^{-1}$ and $2{ }^{\circ} \mathrm{C} \mathrm{s}^{-1}$ from $1050{ }^{\circ} \mathrm{C}$, respectively. In general, the microstructures are very similar in terms of their morphology. The sample cooled faster contains narrower martensite laths (M), whereas bainitic plates (B) are wider. Moreover, the bainite contains some carbides inside the laths (Fig. 9b), which is consistent with the dilatometric results in Fig. 4b. The deformation temperature affected the microstructures to the smaller extent than a cooling rate.

Further morphological details were revealed in the atomic force microscopy. Figure 10 shows an example of the surface topography typical for the investigated samples both deformed at $900{ }^{\circ} \mathrm{C}$ and $1050{ }^{\circ} \mathrm{C}$. Figure $10 \mathrm{a}$ is a 2D map revealing a relief typical for martensitic and bainitic plates, whereas Fig. 10b shows a 3D map of the sample cooled at a rate of $2{ }^{\circ} \mathrm{C} \mathrm{s}^{-1}$ from $900{ }^{\circ} \mathrm{C}$. The difference in height profiles between bainite (B) and martensite-austenite constituents $(\mathrm{M}+\mathrm{RA})$ is $\sim 300 \mathrm{~nm}$. The width of clear martensite plates is in a range of 200-500 nm, whereas the bainite morphology is more complex. The bainitic laths are wider (up to 1-2 $\mu \mathrm{m}$ ) and contain intralath precipitates, which is consistent with the SEM micrographs (Fig. 9b). The increased dislocation density being a result of the strain accumulation during deformation at $900{ }^{\circ} \mathrm{C}$ was identified in the transmission electron microscopy (TEM-Fig. 11). Moreover, films of retained austenite occur between martensitic laths. The thickness of the laths at a cooling rate of $20{ }^{\circ} \mathrm{C} \mathrm{s}^{-1}$ corresponds to $200-300 \mathrm{~nm}$. The presence of some retained austenite fraction was confirmed also in our earlier work using the X-ray diffraction [29].

\section{Mechanical characterization}

The hardness measurements in Fig. 12 show an increased trend together with an increasing cooling rate. This corresponded to the increased fraction of hard martensite. However, the hardness range from the fastest to slowest cooling changes only by $60 \mathrm{HV}$. It means that the steel is not substantially sensitive to the applied cooling rate. This is due to its strong hardenability caused by Mn and Mo additions. For the slowest cooling rate, the bainite is a dominant phase. The lowest hardnesses of 371 and 397 HV10 are obtained for the lowest cooling rate, respectively, at 900 and $1050{ }^{\circ} \mathrm{C}$. When the amount of martensite increases, the hardness increases too. As mentioned above, for the cooling rates higher than 100 and $80{ }^{\circ} \mathrm{C} \mathrm{s}^{-1}$ martensite is the only constituent of microstructure. This results in the highest hardness of 463 and 450 HV10. The hardness of the non-recrystallized austenite transformation products is higher by $\sim 20$ to $30 \mathrm{HV}$ in the whole range of cooling rates.

\section{Conclusions}

The investigated medium-Mn steel is suitable for formation of bainite-based microstructures. The bainite-martensite mixtures are present for the majority of cooling rates applied. The pure martensite is present only for cooling rates higher than $80{ }^{\circ} \mathrm{C} \mathrm{s}^{-1}$. A ferrite fraction smaller than $9 \%$ occurs due to a lack of full austenitization at $1100{ }^{\circ} \mathrm{C}$ caused by $1.7 \% \mathrm{Al}$ addition in the steel. Bainite laths remain thin even at very slow cooling rates. The bainite formed at the slow cooling rates is more globular and contains intralath 
carbides. It means that the steel is not substantially sensitive for cooling conditions from the austenitization region. The same concerns deformation conditions before cooling to room temperature. Very similar microstructures are formed both after deformation at the recrystallized region of $1050{ }^{\circ} \mathrm{C}$ and at non-recrystallized region of $900{ }^{\circ} \mathrm{C}$. Hardness of the steel is in a range between 390 and $460 \mathrm{HV} 10$. It is ca. $20 \mathrm{HV}$ higher for the samples deformed at $900{ }^{\circ} \mathrm{C}$ due to accumulated strain and corresponding increased dislocation density. Deformation in the non-recrystallized region results in slightly higher bainite start temperatures for cooling rates faster than $10^{\circ} \mathrm{C} \mathrm{s}^{-1}$. Martensite start temperature is a little bit lower due to the occurrence of dislocations being obstacles for martensite lath nucleation and growth. The determined DCCT diagrams under conditions of deformation and continuous cooling are useful in further designing the thermomechanical cycles for carbide-free bainitic microstructures with retained austenite, which require more advanced isothermal processing routes.

Acknowledgements The financial support of the National Science Center, Poland, is gratefully acknowledged, Grant No. 2017/27/B/ ST8/02864.

\section{Compliance with ethical standards}

Conflict of interest The authors declare that they have no conflict of interest.

Open Access This article is licensed under a Creative Commons Attribution 4.0 International License, which permits use, sharing, adaptation, distribution and reproduction in any medium or format, as long as you give appropriate credit to the original author(s) and the source, provide a link to the Creative Commons licence, and indicate if changes were made. The images or other third party material in this article are included in the article's Creative Commons licence, unless indicated otherwise in a credit line to the material. If material is not included in the article's Creative Commons licence and your intended use is not permitted by statutory regulation or exceeds the permitted use, you will need to obtain permission directly from the copyright holder. To view a copy of this licence, visit http://creativecommons.org/licenses/by/4.0/.

\section{References}

1. Kang S, Speer JG, Krizan D, Matlock DK, De Moor E. Prediction of tensile properties of intercritically annealed Al-containing 0.19C-4.5Mn (wt\%) TRIP steels. Mater Des. 2016. https://doi. org/10.1016/j.matdes.2016.02.058.

2. Ebner S, Suppan C, Stark A, Schnitzer R, Hofer C. Austenite decomposition and carbon partitioning during quenching and partitioning heat treatments studied via in situ X-ray diffraction. Mater Des. 2019. https://doi.org/10.1016/j.matdes.2019.107862.

3. Steineder K, Krizan D, Schneider R, Beal C, Sommitsch C. On the microstructural characteristics influencing the yielding behavior of ultra-fine grained medium-Mn steels. Acta Mater. 2017. https ://doi.org/10.1016/j.actamat.2017.07.056.
4. Gronostajski Z, Pater Z, Madej L, Gontarz A, Lisiecki L, Lukaszek-Solek A, Luksza J, Mróz S, Muskalski Z, Muzykiewicz W, Pietrzyk M, Śliwa RE, Tomczak J, Wiewiórowska S, Winiarski G, Zasadziński J, Ziółkiewicz S. Recent development trends in metal forming. Arch Civ Mech Eng. 2019. https://doi. org/10.1016/j.acme.2019.04.005.

5. Yang JR, Huang CY, Hsieh WH, Choiu CS. Mechanical stabilization of austenite against bainitic reaction in $\mathrm{Fe}-\mathrm{Mn}-\mathrm{Si}-\mathrm{C}$ bainitic steel. Mater Trans. 1996. https://doi.org/10.2320/matertrans 1989.37.579.

6. Grajcar A, Radwański K. Microstructural comparison of the thermomechanically treated and cold deformed Nb-microalloyed TRIP steel. Materiali in Tehnologije. 2014;48:679-83.

7. Kim H, Suh DW, Kim NJ. Fe-Al-Mn-C lightweight structural alloys: a review on the microstructures and mechanical properties. Sci Technol Adv Mater. 2014. https://doi. org/10.1088/1468-6996/14/1/014205.

8. Hu B, Luo H. A novel two-step intercritical annealing process to improve mechanical properties of medium Mn steel. Acta Mater. 2019. https://doi.org/10.1016/j.actamat.2019.07.014.

9. Shen YF, Qiu LN, Sun X, Zuo L, Liaw PK, Raabe D. Effects of retained austenite volume fraction, morphology, and carbon content on strength and ductility of nanostructured TRIP-assisted steels. Mater Sci Eng, A. 2015. https://doi. org/10.1016/j.msea.2015.04.030.

10. Kaar S, Schneider R, Krizan D, Béal C, Sommitsch C. Influence of the quenching and partitioning process on the transformation kinetics and hardness in a lean medium manganese TRIP steel. Metals. 2019. https://doi.org/10.3390/met9030353.

11. Grajcar A, Zalecki W, Skrzypczyk P, Kilarski A, Kowalski A, Kołodziej S. Dilatometric study of phase transformations in advanced high-strength bainitic steel. J Therm Anal Calorim. 2014. https://doi.org/10.1007/s10973-014-4054-2.

12. Ayenampudi S, Celada-Casero C, Sietsma J, Santofimia MJ. Microstructure evolution during high-temperature partitioning of a medium-Mn quenching and partitioning steel. Materialia. 2019. https://doi.org/10.1016/j.mtla.2019.100492.

13. Avishan B, Garcia-Mateo C, Yazdania S, Caballero FG. Retained austenite thermal stability in a nanostructured bainitic steel. Mater Charact. 2013. https://doi.org/10.1016/j.match ar.2013.04.015

14. Tian J, Xu G, Zhou M, Hu H, Wan X. The effects of $\mathrm{Cr}$ and $\mathrm{Al}$ addition on transformation and properties in low-carbon bainitic steels. Metals. 2017. https://doi.org/10.3390/met7020040.

15. Caballero FG, Bhadeshia HKDH. Very strong bainite. Curr Opin Solid State Mater Sci. 2004. https://doi.org/10.1016/j.cossm s.2004.09.00515.

16. Jahn A, Kovalev A, Weiß A, Scheller PR. Influence of manganese and nickel on the $\alpha$ ' martensite transformation temperature of high alloyed $\mathrm{Cr}-\mathrm{Mn}-\mathrm{Ni}$ steels. Steel Res Int. 2011. https://doi. org/10.1002/srin.201100063.

17. Shah M, Das SK, Chowdhury SG. Effect of alloying elements on microstructure and mechanical properties of air-cooled bainitic steel. Metall Mater Trans A. 2019. https://doi.org/10.1007/s1166 1-019-05177-1.

18. Zhang R, Zheng W, Veys X, Huyberechts G, Springer H, Selleby M. Prediction of martensite start temperature for lightweight $\mathrm{Fe}-\mathrm{Mn}-\mathrm{Al}-\mathrm{C}$ steels. J Phase Equilibr Diffus. 2018. https://doi. org/10.1007/s11669-018-0660-1.

19. Guo H, Zhou P, Zhao A, Zhi C, Ding R, Wang J. Effects of Mn and $\mathrm{Cr}$ on microstructure and mechanical properties of low temperature bainitic steel. J Iron Steel Res Int. 2017. https://doi. org/10.1016/S1006-706X(17)30042-0.

20. Kucerowa L, Jirkova H, Volkmannova J, Vrtacek J. Effect of aluminum and manganese content on the microstructure development 
of forged and annealed TRIP steel. Manuf Technol. 2018. https:// doi.org/10.21062/ujep/146.2018/a/1213-2489/MT/18/4/605.

21. Grajcar A, Zalecki W, Burian W, Kozlowska A. Phase equilibrium and austenite decomposition in advanced high-strength mediumMn bainitic steels. Metals. 2016. https://doi.org/10.3390/met61 00248 .

22. Kokosza A, Pacyna J. Formation of medium carbon TRIP steel microstructure during annealing in the intercritical temperature range. Arch Metall Mater. 2014. https://doi.org/10.2478/ amm-2014-0170.

23. Xiao F, Liao B, Qiao G, Guan S. Effect of hot deformation on phase transformation kinetic of $86 \mathrm{CrMoV} 7$ steel. Mater Charact. 2006. https://doi.org/10.1016/j.matchar.2006.02.003.

24. Snopiński P, Król M, Tański T, Krupińska B. Effect of cooling rate on microstructural development in alloy AlMg9. J Therm Anal Calorim. 2018. https://doi.org/10.1007/s10973-018-7313-9.

25. Kawulok P, Podolinsky P, Kajzar P, Schindler I, Kawulok R, Sevcak V, Opela P. The influence of deformation and austenitization temperature on the kinetics of phase transformation during cooling of high-carbon steel. Arch Metall Mater. 2018. https://doi. org/10.24425/amm.2018.125100.
26. Matsuoka Y, Iwasaki T, Nakada N, Tsuchiyama T, Takaki S. Effect of grain size on thermal and mechanical stability of austenite in metastable austenitic stainless steel. ISIJ Int. 2013. https ://doi.org/10.2355/isijinternational.53.1224.

27. Kowalczyk K, Jabłońska M, Rusz S, Junak G. Influence of recrystallization annealing on the properties and structure of low-carbon ferritic steel. Arch Metall Mater. 2018. https://doi.org/10.24425/ amm.2018.125130.

28. Opiela M, Grajcar A. Elaboration of forging conditions on the basis of the precipitation analysis of MX-type phases in microalloyed steels. Arch Civ Mech Eng. 2012. https://doi.org/10.1016/j. acme.2012.06.013.

29. Kozłowska A, Janik A, Radwański K, Grajcar A. Microstructure evolution and mechanical stability of retained austenite in medium-Mn steel deformed at different temperatures. Materials. 2019. https://doi.org/10.3390/ma12183042.

Publisher's Note Springer Nature remains neutral with regard to jurisdictional claims in published maps and institutional affiliations. 